\title{
COVID-19 E A INVISIBILIZAÇÃO DA PESSOA COM DEFICIÊNCIA: AS FORMAS DE DIVULGAÇÃO DE INFORMAÇÃO EM SITE OFICIAL
}

\author{
COVID-19 AND THE INVISIBILIZATION OF PEOPLE WITH \\ DISABILITIES: THE WAYS OF DISCLOSURE \\ OF INFORMATION ON OFFICIAL WEBSITE

\begin{abstract}
COVID-19 Y LA INVISIBILIZACIÓN DE PERSONAS CON DISCAPACIDAD: LAS FORMAS DE DIVULGACIÓN DE INFORMACIÓN EN SITIO WEB OFICIAL
\end{abstract}

\author{
JOSIVAN JoÃo MONTEIRO RAIOL ${ }^{\mathrm{I}}$ \\ ROSIMEIRE MARIA ORLANDO ${ }^{\mathrm{I}}$ \\ EDUARDO THOMAZINI ${ }^{\mathrm{I}}$
}

${ }^{\mathrm{I}}$ Universidade Federal de São Carlos (UFSCar), São Carlos/SP - Brasil

\begin{abstract}
Resumo Historicamente há dificuldade no reconhecimento de grupos considerados minoritários, aqui sublinhados: as pessoas com deficiências, no que cerne a legitimar suas ações, enquanto seres sociais e pertencentes a sociedades. Por este ângulo e baseado em perspectivas e conceitos críticos, que levam à compreensão do peso discursivo e o reflexo destas nas ações político-governamentais, este estudo objetivou analisar e mapear criticamente em site oficial a divulgação de informações sobre o COVID-19 e pessoa com deficiência. A análise realizada mapeou o site com a utilização de dois descritores: pessoa com deficiência e deficiência. Os dados revelaram que dos 30 ícones pesquisados, somente dois possuíam informações que relacionavam a pandemia do novo coronavírus com o público em questão, o que possibilitou afirmar a violência simbólica vivenciada pelas pessoas com deficiência, a relação desigual no combate e prevenção da COVID-19, a manutenção de poder da classe dominante e a constituição de uma identidade invisibilizada.
\end{abstract}

Palavras-Chave: Pessoa com deficiência; COVID-19; Website; Análise crítica.

ABSTRACT Historically, there is difficulty in recognizing groups considered minority groups, underlined here: people with disabilities, as regards the legitimacy of their actions, as social beings and belonging to societies. Based on critical perspectives and concepts, which lead to an understanding of the discursive weight and their reflection in political-governmental actions, this study aimed to critically analyze and mapping the disclosure of information 
about COVID-19 and people with disabilities on an official website. The analysis carried out mapped the website with the utilization of two discribers: people with disabilities and disabilities. The data revealed that of the 30 icons surveyed, only two had information that related the pandemic of the new coronavirus with the public in question, which makes it possible to affirm the symbolic violence experienced by the people with disabilities, the unequal relationship in the combat and prevention of COVID-19, the maintenance of power of the ruling class and the constitution of an invisibilized identity.

Keywords: Person with desability; COVID-19; Website; Critical analyses.

RESUMEN Históricamente, existe dificultad para reconocer a los grupos considerados minoritarios, aquí subrayados: las personas con discapacidad, en cuanto a la legitimidad de sus acciones, como seres sociales y pertenecientes a sociedades. Desde este ángulo y con base en perspectivas y conceptos críticos, que conducen a la comprensión del peso discursivo y su reflejo en las acciones político-gubernamentales, este estudio tuvo como objetivo analizar y mapear críticamente en el sitio web oficial la divulgación de información sobre el COVID-19 y las personas con deficiencia. El análisis realizado mapeó el sitio utilizando dos descriptores: discapacitados y discapacitados. Los datos revelaron que de los 30 íconos encuestados, solo dos tenían información que relacionaba la pandemia del nuevo coronavirus con el público en cuestión, lo que permitió afirmar la violencia simbólica que viven las personas con discapacidad, la relación desigual en la lucha y prevención del COVID-19, el mantenimiento del poder de la clase dominante y la constitución de una identidad invisible. Palabras Clave: Person con discapacidad; COVID-19; Sitio web; Análisis critico.

\section{INTRODUÇÃo}

A doença provocada pelo Coronavirus Disease 2019 (COVID-19) foi identificada pela primeira vez em dezembro de 2019 na cidade de Wuhan, na China, e em janeiro de 2020 a Organização Mundial da Saúde (OMS, 2020) declarou como uma emergência em saúde pública de interesse internacional. A rápida escalada da COVID-19, com disseminação em nível global, fez com que a OMS classificasse a doença no dia 11 de março de 2020 como uma pandemia.

No dia 26 de fevereiro de 2020 o Ministério da Saúde confirmou o primeiro caso de COVID-19 no Brasil, tratava-se um de um homem que havia viajado para Itália, local que depois de Wuhan na China haveria de se tornar um dos epicentros de contágio do novo coronavírus. Pouco mais de três meses após o primeiro caso de COVID-19 no Brasil, as atenções se voltam para o país que se tornou o epicentro da pandemia conforme afirmou o diretor da OMS Michael Ryan.

Neste sentido, ao analisar a crise sanitária do coronavírus no mundo é possível perceber a disparidade das ações político governamentais para a desaceleração do contágio do vírus. Há necessidade de considerar a clara diferença econômica entre os países considerados ricos e os países em desenvolvimento, diferença que incide na forma como a pandemia é tratada e na prioridade em preservar vidas e/ou a economia. A complexa relação entre 
manter a economia e acatar com o que recomenda a OMS sobre o isolamento social provoca divergências no que tange ao cumprimento ou não das medidas tanto pelos governos quanto pela população, de qualquer forma os impactos estão para além da visão econômica e sugerem percepção macro dos efeitos que a pandemia tem provocado, como por exemplo, na saúde mental e na educação escolar das pessoas.

Contudo, é relevante ressaltar que em meio à diferença econômica global, as prioridades políticas com que cada país adota ou não medidas para freiar o contágio da COVID-19 e os prejuízos de diferentes ordens, emerge a necessidade de relacionar estes aspectos ao atendimento, acesso à informação, educação e apoio que estão sendo destinados a pessoas com deficiência. A fim de amplificar esta discussão, pautamos a relação da pessoa com deficiência e do coronavírus no contexto brasileiro.

\section{COVID - 19 E O CONTEXTO BRASILEIRO}

Ao considerar as pandemias, especialmente as gripais, Neumann et al. (2009) as compreende como eventos naturais que ocorrem periodicamente, o que nos faz refletir acerca dos impactos social, econômico e político no Brasil, pois ao problematizar este aspecto, compreendemos em linhas gerais que, na vigência de pandemias, a saúde física das pessoas e o combate ao agente patogênico são os focos primários de atenção de gestores e profissionais da saúde, o que possibilita analisar sobre as adversidades de um evento pandêmico como o COVID-19 nas vidas de pessoas com deficiência.

Ao relacionar estas questões com o avanço do neoliberalismo a partir da década de 80 , compreende-se este fenômeno a partir do discurso da suposta expansão desnecessária dos direitos sociais e a participação do Estado, tida como secundária e insuficiente no desenvolvimento de políticas de proteção social (SANTOS, 2020). Este discurso reprodutivista, possibilita a manutenção da ordem neoliberal na perspectiva de cada vez mais o Estado entregar os serviços para os comandos do setor privado.

Desta maneira, Santos (2020) traduz as complexidades da relação entre o neoliberalismo, a pandemia e grupos considerados invisibilizados "Sabemos que a pandemia não é cega e tem alvos privilegiados, mas mesmo assim cria-se com ela uma consciência de comunhão planetária, de algum modo democrática" (p. 7). Todavia, o sentimento de comunhão presente no discurso mascara a antidemocrática luta contra o vírus, pois há de se considerar os aspectos político-sociais que podem ser facilitadores e/ou impeditivos ao acesso à informação, saúde, educação. É neste sentido, que o Relatório Mundial sobre a Deficiência (2011) relaciona a deficiência com a funcionalidade, e com os aspectos ambiental e pessoal.

compreende funcionalidade e deficiência como uma interação dinâmica entre problemas de saúde e fatores contextuais, tanto pessoais quanto ambientais. Promovido como um "modelo biológico-psíquico-social", o relatório representa um compromisso viável entre os modelos médico e social. A incapacidade é um termo abrangente para deficiências, limitações para realizar, e restrições para participar de certas atividades, que engloba os aspectos negativos da inte- 
ração entre um indivíduo (com um problema de saúde) e os fatores contextuais daquele indivíduo (fatores ambientais e pessoais). (SÃO PAULO, 2011, p. 4).

O entendimento da deficiência a partir de fatores contextuais que coadunam entre os modelos social e médio, permite uma visão ampla da pessoa com deficiência, afinal se compreende que as limitações e restrições ocasionadas pela deficiência abrangem as formas de interação humana. Em outro aspecto a Lei $N^{\circ} 13.146$ de 6 de julho de 2015 considera pessoa com deficiência aquela que tem impedimento de longo prazo de natureza física, mental, intelectual ou sensorial, o qual, em interação com uma ou mais barreiras, pode obstruir sua participação plena e efetiva na sociedade em igualdade de condições com as demais pessoas. Ao trazer conceitos da pessoa com deficiência, vislumbramos ampliar o leque de concepções que permeiam os aspectos legais, incidem diretamente nas formas de representação e de constituição de políticas públicas para esse grupo. Neste sentido e partindo desses pressupostos, segundo a OMS existiam mais de 1 bilhão de pessoas no mundo que viviam nesta condição em 2011, ou seja, uma em cada sete pessoas no mundo, número que certamente cresceu nos últimos anos.

Em consonância com este dado, a Organização das Nações Unidas (ONU. 2020) afirma que "Ter alguma deficiência aumenta o custo de vida em cerca de um terço da renda, em média. [...]" Além disso, mais de 50\% das pessoas com deficiência não conseguem pagar por serviços de saúde e também que $80 \%$ desses sujeitos vivem em países em desenvolvimento. Ao contextualizar estes números com nossa realidade, o Instituto Brasileiro de Geografia e Estatística (IBGE), no censo de 2010, apontou que quase 46 milhões de brasileiros declararam possuir algum tipo de deficiência, cerca de $24 \%$ da população. Ou seja, com as informações citadas acima, fica evidente que uma grande parcela da população com algum tipo de deficiência tem uma elevada chance de ser proveniente da classe baixa nestes países emergentes, não tendo acesso, muitas vezes, a educação, cerca de $90 \%$ nem saúde, como citado anteriormente (ONU, 2016). A ONU (2016) afirma ainda que a falta de estatísticas sobre pessoas com deficiência contribui para a invisibilidade dessas pessoas, isso representa um obstáculo para planejar e implementar políticas de desenvolvimento que melhoram as vidas destes indivíduos.

É nesse aspecto que, a cultura é atribuidora de significações especiais, produzindo determinadas atitudes em detrimento de outras; hierarquizando as que devam ser exaltadas por sua importância e pertencimento ao grupo social representado ou as que serão inibidas por não dialogarem com o que é pretendido enquanto norma de benefício a esse mesmo grupo (RODRIGUES, 2006). Tal conduta se reflete na tomada de decisões, nas políticas públicas, na manutenção dos privilégios e na invisibilização dos que se mantém à margem da sociedade.

Sobre o quanto as significações produzem atitudes e refletem na tomada de decisões políticas, cabe mostrar a necessidade do posicionamento do Conselho Nacional dos Direitos da Pessoa com Deficiência (CONADE) que, por meio de nota, enfatizou a carência de medidas emergenciais de proteção à população brasileira, particularmente aos que se encontram em situação de maior vulnerabilidade ou desvantagem, a exemplo pessoas com deficiência. A nota pública do CONADE reitera a garantia de atendimento prioritário já previsto na LBI e apresenta recomendação para inclusão desse público em atendimentos prioritários, especialmente nas unidades de atendimento em saúde (CONADE, 2020). 
Igualmente, o CONADE comunicou a urgência de inclusão das pessoas com deficiência no grupo de risco no âmbito da COVID - 19 à Câmara dos Deputados por meio da Comissão Externa destinada a acompanhar ações preventivas da vigilância sanitária e possíveis consequências para o Brasil quanto ao enfrentamento da pandemia causada pelo coronavírus. Chega a ser redundante precisar expor o pedido do CONADE, ora se o Ministério da Saúde não considera pessoas com deficiência como prioridade no atendimento, o que seria prioritário para este público?

A invisibilização da saúde das pessoas com deficiência em meio à pandemia é reflexo da complexa relação neoliberal, a manutenção de poder e a naturalização da ausência estatal. Nesta perspectiva, corrobora-se com Santos (2020) ao considerar que qualquer quarentena é discriminatória para uns grupos sociais, haja vista que estes padecem de especial vulnerabilidade e ao contextualizar socialmente estes grupos é possível afirmar a somatização das dificuldades que se relacionam à limitação ocasionada pela deficiência, pobreza, raça e gênero.

Trata-se da forma como a sociedade os discrimina, não lhes reconhecendo as suas necessidades especiais, não lhes facilitando acesso à mobilidade e às condições que lhes permitiriam desfrutar da sociedade como qualquer outra pessoa. De algum modo, as limitações que a sociedade lhes impõe fazem com que se sintam a viver em quarentena permanente. Como viverão a nova quarentena, sobretudo quando dependem de quem tem de violar a quarentena para thes prestar alguma ajuda? Como já á muito se habituaram a viver em condições de algum confinamento, sentir-se-ão agora mais livres que os «não-deficientes» ou mais iguais a eles? Verão tristemente na nova quarentena alguma justiça social? (SANTOS, 2020. p. 20)

Relacionar a pessoa com deficiência com os aspectos sociais em que elas estão inseridas, oportuniza refletir sobre como estão sendo divulgadas as informações sobre o COVID - 19 para este grupo no Brasil? Esta reflexão sugere entrelace dessas perspectivas para compreender as ações que estão sendo desenvolvidas neste âmbito.

Assim, a fim de obter referências sobre os métodos de divulgação de informações em sites, foi encontrado o Wolrd Wide Web Consortium (W3C), que corresponde a uma comunidade internacional a qual possui uma equipe contratada e também conta com a ajuda do público para desenvolver padrões web. Esta comunidade tem o objetivo de guiar a web a ter seu total potencial explorado, dessa forma a partir da W3C foi possível perceber que na internet não há uma forma padrão de disponibilização de conteúdo, ficando a critério dos criadores a elaboração da mesma, neste sentido o W3C traz definições bem amplas sobre o assunto e também uma grande quantidade de meios para que haja essa liberdade na hora de criar um layout e decidir quais informações apresentar. Dito isso, é evidente que fica a critério dos órgãos responsáveis a divulgação das informações governamentais, quais informações e de que formas disponibilizá-las nos sites oficiais de cada nação.

É diante deste cenário e após reflexões sobre esta temática que esta investigação objetivou verificar e analisar criticamente em site oficial a divulgação de informações sobre o COVID-19 e pessoa com deficiência e mapear informações da pandemia sobre o público em questão. 


\section{Metodologia}

Ao dispor analisar as informações em site oficial sobre o coronavírus no Brasil e a relação da pandemia e pessoa com deficiência, esta investigação optou pela abordagem qualitativa por empregar diferentes concepções filosóficas, estratégias de investigação e métodos de coleta, análise e interpretação dos dados (CRESWELL, 2010). Para Koller, Couto e Hohendorff (2014), em pesquisas qualitativas é possível observar, coletar e descrever informações sobre como as diferentes variáveis podem estar relacionadas. Além disso, ao utilizar esta abordagem, o pesquisador se propõe a refletir sobre os dados obtidos e aprofundar a compreensão sobre o grupo estudado.

O delineamento foi do tipo descritivo por propor a estudar o atendimento, orientação e prevenção do novo coronavírus dos órgãos públicos, aqui delimitado pelo site institucional do Ministério da Saúde, a uma determinada comunidade (GIL, 2008). Segundo Cervo e Bervian (1983) pesquisa descritiva é aquela que analisa, observa, registra e correlaciona aspectos (variáveis) que envolvem fatos ou fenômenos, sem manipulá-los. Os fenômenos humanos ou naturais são investigados sem a interferência do pesquisador que apenas "procura descobrir, com a precisão possível, a frequência com que um fenômeno ocorre, sua relação e conexão com outros, sua natureza e características". (CERVO; BERVIAN, 1983, p. 55).

Dessa maneira, os dados foram coletados em site oficial do Ministério da Saúde sobre o coronavírus no Brasil https://coronavirus.saude.gov.br/ como mostra a figura 1.

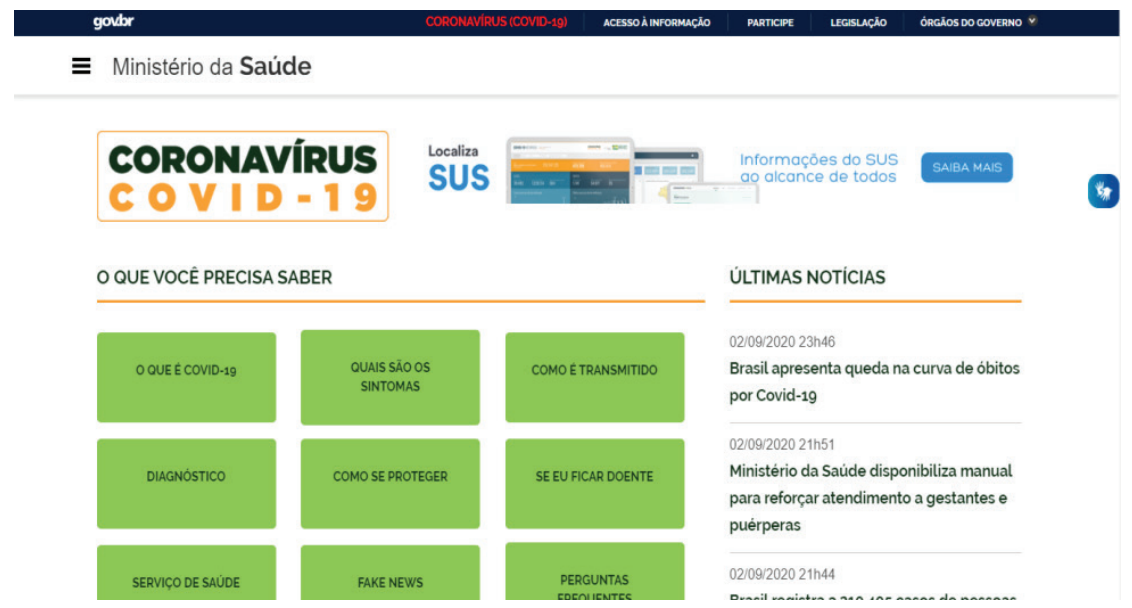

Figura 1 - Página inicial do site oficial do Ministério da Saúde sobre coronavírus no Brasil

Fonte: https://coronavirus.saude.gov.br/

A partir do acesso ao site foi possível realizar pesquisa e posterior análise crítica dos dados sobre o coronavírus e pessoas com deficiência. Destarte, para obtenção dos dados foram utilizadas as palavras-chave: pessoa com deficiência e deficiência. A coleta iniciou no dia 02.07.2020, finalizou no dia 12.07.2020 e analisou os seguintes espaços (ícones) do site: Últimas Notícias; O que você precisa saber; Transparência; Portarias; Profissionais e Gestores da Saúde; Publicações Evidências Científicas; Pesquisa e Inovação e Assistência Farmacêutica. 


\section{RESULTADOS E DISCUSSÃo}

O primeiro item analisado foi: Últimas Notícias e Acesse mais notícias. Neste ícone e sublink respectivamente foi utilizado à delimitação temporal que considerou reportagens a partir do primeiro caso de COVID-19 confirmado no Brasil que data do dia 26.02.2020 até $30.06 .2020^{1}$, após a realização da pesquisa utilizando as palavras-chave foram encontradas 21 publicações, estas foram classificadas de acordo com o tema: Pessoa com Deficiência e H1N1, PRONON e PRONAS - PCD, Pessoa com Deficiência e Coronavírus e outras publicações como mostra a Tabela 1.

\section{Tabela 1 - Icone "Últimas Notícias"}

\begin{tabular}{c|c}
\hline Classificação das publicações & Quantidade \\
\hline Pessoa com Deficiência e H1N1 & 13 \\
\hline PRONON e PRONAS - PCD” & 2 \\
\hline Pessoa com Deficiência e Coronavírus & 2 \\
\hline outras publicações & 4 \\
\hline
\end{tabular}

Fonte: https://coronavirus.saude.gov.br/

Do total de publicações, duas foram classificadas como "Pessoa com Deficiência e Coronavírus", por reunirem as palavras-chave em questão e a relação com a temática investigada, o que nos possibilitou analisar o processo de invisibilização da pessoa com deficiência. Outro fator que necessita de atenção é que dentre as publicações encontradas, uma delas tem relação com a manutenção de serviços considerados essenciais e de apoio à pessoa com deficiência e a outra faz referência ao lançamento de aplicativo para a orientação de prevenção e características do coronavírus, esta última informa que o aplicativo está disponível em outras línguas, incluindo a Língua Brasileira de Sinais - LIBRAS.

Ao complexificar a relação das informações divulgadas em site oficial do Ministério da Saúde sobre o coronavírus e pessoa com deficiência, ancoramos nossa análise em Bourdieu (2011), ao afirmar que os seres humanos e as coisas ocupam um lugar tanto no espaço físico, quanto no espaço social. O espaço físico está ligado à localização, numa relação de exterioridade com os outros e o espaço social tem um indicativo de posição, ocorrendo uma distinção e exclusão de posições sociais, ou seja, em síntese o lugar destinado a pessoas com deficiência no espaço social se refere a uma relação de inferioridade, de invisibilização, o que sugere a íntima ligação a classe social da pessoa com deficiência. A exterioridade com os outros pode ser analisado a partir da redução do grupo ao considerar a LIBRAS como língua de acesso à informação de um grupo todo, outro fator refere-se ao único registro sobre os serviços essenciais para o atendimento à pessoa com deficiência, ou seja, não há preocupação com protocolos específicos e/ou formas alternativas de atendimento a este público em meio à pandemia.

1 Até o momento da realização da coleta a última publicação encontrada utilizando as palavras-chaves no ícone "Últimas Notícias" data do dia 30.06.2020. 
Para Bentes e Hayashi (2012), a invisibilização do corpo deficiente é uma imposição tão rigorosa que mesmo grupos que lutam contra as desigualdades também assumem posturas de não reconhecer tais corpos. O não reconhecimento também equivale a espaços governamentais que são utilizados como ferramentas para manutenção de status, o que possibilita analisar a constituição de uma cultura da invisibilização como explicita Tomás (2008, p.1).

\begin{abstract}
No império visual da sociedade ocidental contemporânea ser invisível tende a significar ser inexistente ou insignificante. Este sentimento de invisibilidade é provocado pelo não-reconhecimento de outrem sendo esta atitude um produto da cultura e do passado biográfico daquele que-não-vê. Existem duas possibilidades para que um indivíduo seja invisível quando na realidade objectiva é fisicamente visível. Por um lado pode ser o resultado de um acto voluntário. Por outro lado pode ser a consequência de uma intersubjectividade constituinte, o que implica que o acto de "não-ver" é uma perspectiva colectiva e partilhada dando origem a uma alteridade invisível. (TOMÁS, 2008, p. 1).
\end{abstract}

A insignificância destinada às pessoas com deficiência durante a crise sanitária reflete contextos históricos, representações e uma cultura da invisibilização, no entanto apontar estas questões permite compreender a relação da comunicação como meio de manutenção de poder. Ora, se nesta investigação temos como fonte de dados o site institucional do Ministério da Saúde sobre o Coronavírus no Brasil, é cabível anunciar a utilização dessa ferramenta de comunicação como meio para a manutenção da invisibilização, ou seja, a invisibilização da pessoa com deficiência é institucionalizada de tal maneira que os atos de submissão, de obediência, são atos de conhecimento e de reconhecimento dos quais mobilizam estruturas cognitivas possíveis de serem aplicadas a todas as coisas e em particular às estruturas sociais. (BOURDIEU, 2001).

Tal afirmativa pode ser comprovada na tabela 2 ao apontarmos que outros três ícones apresentaram resultados equivalentes.

Tabela 2 - Janelas onde foram encontrados registros

\begin{tabular}{c|c}
\hline Ícones & Sublinks \\
\hline CAPACITAÇÃO & Vídeos sobre a Saúde da Pessoa com Deficiência \\
\hline EVIDÊNCIAS CIENTÍFICAS & $\begin{array}{c}\text { Informe diário de evidências; diretrizes para o diagnóstico } \\
\text { e tratamento da COVID-19; síntese de evidências e notas } \\
\text { técnicas }\end{array}$ \\
\hline $\begin{array}{c}\text { MANEJO CLÍNICO } \\
\text { E TRATAMENTO }\end{array}$ & Não se aplica \\
\hline
\end{tabular}

Fonte: https://coronavirus.saude.gov.br/

A tabela 2 evidencia que no processo de análise do site verificamos uma área destinada a profissionais que atuam na linha de frente do combate à pandemia, este nomeado de: Profissionais e Gestores da Saúde, nele foi possível encontrar o ícone "Capacitação" onde há diversos sublinks que atendem grupos específicos como: pessoas com deficiência e indígenas. Nesta mesma janela foram encontrados cinco vídeos relacionados à saúde da 
pessoa com deficiência e protocolos de segurança para o COVID - 19. Os vídeos sugerem atenção a pessoas que possuem mobilidade reduzida, deficiência auditiva, deficiência visual deficiência intelectual, Transtorno do Espectro Autista (TEA) e limitações na comunicação. Apesar de as orientações estarem acessíveis em LIBRAS e contextualizarem de acordo com a deficiência, as mesmas não refletem a condição financeira da maioria da população, pois as orientações encontram-se disponíveis apenas em um ícone, e somente por meio de vídeos. Neste sentido, Bourdieu (2010) afirma que a

violência suave, insensível, invisível a suas próprias vítimas, que se exerce essencialmente pelas vias puramente simbólicas da comunicação e do conhecimento, ou, mais precisamente, do desconhecimento, do reconhecimento ou, em última instância, do sentimento (BOURDIEU, 2010, p. 07-08).

A violência simbólica presente nas orientações do Ministério da Saúde está em sugerir o uso de vídeo chamada com o objetivo de minimizar a sensação de distanciamento social entre a comunidade surda e não objetiva-se com este apontamento minimizar as estratégias adotadas pelo Ministério da Saúde, mas levantar o questionamento sobre o acesso a smartphones, tablets, notbooks e outros aparelhos que auxiliem a comunicação, além de considerar que para efetivar tal orientação há necessidade de acesso a internet, ou seja, de acordo com o IBGE (2018), 20,9\% dos domicílios brasileiros não possuem conexão com a internet, outro dado importante refere-se ao fato de que ainda segundo IBGE (2018), como parte da Síntese de Indicadores Sociais - SIS que analisa as desigualdades a partir de indicadores de distribuição de rendimento, acesso a bens e serviços, pobreza monetária e restrições acesso em várias dimensões, para mais da metade das pessoas $(57,6 \%)$, os rendimentos domiciliares percapita era igual ou inferior ao valor do salário mínimo vigente, ou seja, R\$ 954,00 (SIS/IBGE, 2019). Com uma renda tão baixa é quase improvável que esta parcela da população tenha acesso a recursos tecnológicos e internet de qualidade.

Em compensação, ao analisar esta questão corroboramos com Saviani (2020. p.8) ao afirmar a importância de "[...] prover o acesso à internet ao maior número possível de residências [..]". Neste sentido, entende-se que o Estado precisaria assumir o acesso à internet e recursos tecnológicos para essa parcela da população pobre (inclui-se pessoas com deficiência), pois, não se tem a possibilidade nem de minimizar o distanciamento social, conforme sugerido, e muito menos de assistir aos vídeos de orientação disponibilizados pelo Ministério da Saúde e ao mencionar essa questão agrega-se a condição de deficiência e o consequente agravamento da desigualdade.

Ademais é evidente que a pandemia vem agravar a marginalização da pessoa com deficiência e analisar esta questão permite concordar com Bourdieu (2010) ao compreender a violência simbólica como uma força socialmente tolerável, especialmente por reafirmar o processo de dominação de uma classe sobre a outra. Há nesse discurso a ideia de atendimento a necessidade de orientação a um determinado público, haja vista a disponibilização de vídeos explicativos, em contrapartida se desconsidera a massa populacional que não tem acesso a esse serviço. Assim, a força simbólica constitui uma forma de poder que se exerce sobre os corpos, diretamente, e como que por encanto, a despeito de qualquer constrição física; mas o encanto opera buscando apoiar-se em disposições previamente constituídas, que ele desencadeia como se fossem molas. (BOURDIEU, 2001). 
A violência simbólica também pôde ser verificada no sublink "Manejo clínico e tratamento" onde obtivemos o acesso a diversos manuais, guias e diretrizes para diagnóstico e tratamento da COVID-19, nele ainda há vários outros links com cartilhas e documentos orientativos para profissionais e gestores da saúde, sob o subtítulo "Orientações Gerais", onde foi possível identificar a presença das palavras-chave nos documentos, no entanto, não correspondia ao objetivo da pesquisa, haja vista que o termo deficiência se referia à ausência de vitamina e/ou imunodeficiência.

Ao pesquisar no item Evidências Cientificas, foram encontrados quatro subitens: informe diário de evidências; diretrizes para o diagnóstico e tratamento da COVID-19; síntese de evidências e notas técnicas. Durante a varredura foi encontrada uma menção no subitem informe diários de evidências na publicação do dia 02.07.2020 relacionado ao estudo realizado sobre o uso da hidroxicloroquina (HCQ) e breves episódios de deficiência visual. Nos demais subitens não foram encontrados assuntos oriundos a pesquisa.

Os dados revelam a sobreposição de classes e o uso da comunicação institucional como meio de manutenção de poder, reverbera a discrepância social brasileira, o abismo do acesso e a dupla marginalização quando se trata da posição social e a condição de pessoa com deficiência. Neste sentido, a invisibilização refletida nas publicações do Ministério da Saúde nos permitiu a aproximação com Hall (2005) ao relacionar a externalização da interação entre a sociedade e a pessoa com deficiência.

De acordo com essa visão, que se tornou a concepção sociológica clássica da
questão, a identidade é formada na "interação" entre o eu e a sociedade. O su-
jeito ainda tem um núcleo ou essência interior que é o "eu real", mas este é for-
mado e modificado num diálogo contínuo com os mundos culturais "exteriores"
e as identidades que esses mundos oferecem (HALL, 2005, p. 11).

Esta perspectiva da interação e da construção da identidade invisível sobre a pessoa com deficiência é confirmada ao refletirmos que, dos 30 ícones verificados, quatro ícones apontaram resultados de acordo com a delimitação de busca realizada nesta pesquisa, sendo que destes achados apenas dois ícones apresentavam orientação e prevenção sobre o coronavírus e serviços essenciais destinados à pessoa com deficiência. Apesar de o conteúdo estar direcionado à saúde do público em questão, um dos materiais se encontrava em ícone direcionado para profissionais e gestores da saúde.

A reflexão aqui apresentada demonstra que a construção da identidade invisibilizada é um projeto da classe dominante, ou seja, a ausência de menção de pessoas com deficiência em site institucional sobre uma das maiores crises sanitárias mundiais nos últimos cem anos é uma forma de manutenção de poder. Neste sentido, falar sobre este prospecto possibilita coadunar com a discussão bourdieusiana ao compreender o espaço social e as lutas simbólicas, logo mesmo que nesta investigação o público pesquisado se refira a pessoas com deficiência, podemos certamente pensar que tal reflexão é cabível a outros coletivos sociais considerados minoritários como: indígenas, LGBTQI+, mulheres negras, dentre outras classificações. Desse modo, para além de pensar a crise sanitária como mecanismo da manutenção de poder, pode-se a firmar que tal estratégia agrava ainda mais as formas de dominação como mostra Saviani (2020). 
É o que está ocorrendo com a crise sanitária que tende a ser utilizada pelos setores dominantes da sociedade para aprofundar as formas de dominação enquanto as classes dominadas constatam que se escancara a incapacidade da (des) ordem social dominante de resolver os problemas agravados pela pandemia [...]. (SAVIANI, 2020. 5).

Com isso, o Estado por meio da comunicação cria condições de uma orquestração imediata do habitus que constitui, por sua vez, o fundamento de um consenso sobre esse conjunto de representações sobre a pessoa com deficiência capaz de conformar o senso comum (BOURDIEU, 2001). À vista disso, o Estado contribui diretamente para a produção e reprodução dos instrumentos de construção da realidade social, em outros termos se naturaliza a invisibilização da pessoa com deficiência.

Assim, os dados permitem analisar as estruturas estruturantes do Estado utilizadas para a organização do processo de dominação, todavia, para Bourdieu (2001) é necessário compreender a submissão imediata obtida pela ordem estatal e que as tais estruturas cognitivas não são formas da consciência, mas disposições do corpo, esquemas práticos, e que a obediência que concedemos a ordem estatal não é submissão mecânica a uma força, nem como consentimento consciente a uma ordem. Toda esta submissão é um produto do acordo estabelecido entre as estruturas cognitivas a partir da evolução da história coletiva e individual nos corpos e as disposições objetivas do mundo o qual elas se aplicam.

Logo, sistemas governamentais são utilizados para a manutenção de status da classe dominante, pois ao analisar a identidade invisibilizada da pessoa com deficiência temos a reprodução desta representação que é importante ressaltar não recai somente nos aspectos relacionados à saúde, mas nas formas de interação na educação, no trabalho, na família. Estas ações ou a ausência delas corroboram com a perspectiva da violência simbólica, do poder simbólico e transitam dentro do mecanismo reprodutivista da manutenção de poder.

\section{CONSIDERAÇões FINAIS}

Compreender os modos pelos quais as relações de poder e dominação são efetivadas constituem pesquisas de grande relevância, pois o desvelamento dessas relações nos mostram os mecanismos multifacetados, e apesar de estarem separados pelos vários elementos possuem um único objetivo que é a manutenção de poder, além de estarem presentes nos mais diversos setores sociais.

Ao analisar o site institucional do Ministério da Saúde sobre o coronavírus é possível afirmar a dominação de uma classe sobre outra, especialmente por considerar a identidade construída acerca do corpo deficiente. Esta relação assimétrica entre corpos deficientes e corpos não deficientes é legitimada e institucionalizada ao concluirmos a invisibilidade da pessoa com deficiência em site institucional sobre o coronavírus no Brasil.

A violência silenciosa e negligente apresentada nesta investigação resulta em problemas sociais graves que perpassam a questão da saúde e ao entrelaçar os dados com as teorias de Bourdieu e Hall tem-se a dimensão da violência e da estruturação de manutenção e reprodução. É importante ressaltar que o processo de coleta de dados em site oficial e a posterior análise dos dados revelam não somente a invisibilização da pessoa com 
deficiência em meio a pandemia, mas são frutos de um processo histórico e necessitam diariamente ser discutidos, pois ao pesquisar sobre pessoa com deficiência, cabe questionar o sistema de dominação em que toda a sociedade está exposta, afinal apesar de implicar diretamente na vida desses indivíduos, há de se considerar o quanto esta questão expõe os abismos relacionados a pobreza, acesso a comunicação, serviços essenciais. Ousa-se afirmar que tal discussão perpassa pelo direito à escolarização, acesso à informação, ao mercado de trabalho, todas estas questões estão relacionadas as formas de interação com o outro, as representações que se constituem e reproduzem historicamente e como se organizam para manter a hegemonia.

Desta maneira, a reflexão desta temática necessita de maior discussão, no sentido de abranger outras esferas, pois se compreende que mesmo em setores que supostamente deveriam contribuir para o rompimento do mecanismo reprodutivista se apresentam como parte ativa na manutenção de poder da classe dominante. Espera-se que além de apresentar e analisar como foram divulgadas as informações sobre a crise sanitária do COVID-19, outras formas de análise crítica possam ampliar a discussão.

\section{REFERÊNCIAS}

BENTES, J. A. O. HAYASHI, M. C. P. I. Normalidade e Disnormalidade: Formas de trabalho docente na educação de surdos. Campina Grande: EDUEPB, 2012.

BOURDIEU, P. Meditações Pascalianas. Traduação Sérgio Miceli. Rio de Janeiro: Bertrand Brasil, 2001.

BOURDIEU, P. A dominação masculina. 7ª ed. Rio de Janeiro: Bertrand Brasil, 2010.

BOURDIEU, P. A miséria do mundo. 8. ed. Petrópolis: Vozes, 2011.

BRASIL. Relatório mundial sobre a deficiência. São Paulo: SEDPcD, 2012. Disponível em:

https://www.un.org/development/desa/disabilities/covid-19.html. Acesso em 09.06.2020.

BRASIL. LEI No 13.146, DE 6 DE JULHO DE 2015. Institui a Lei Brasileira de Inclusão da Pessoa com Deficiência (Estatuto da Pessoa com Deficiência). Brasília, 2015

COMO a América do Sul se tornou o novo epicentro da pandemia de coronavírus. BBC News Brasil. 22 maio. 2020. Disponível em: https://www.bbc.com/portuguese/internacional-52779245. Acesso em 09.06.2020.

CRESWELL, J. W. Projeto de pesquisa: métodos qualitativo, quantitativo, misto; traduação Magda Lopes. - $3^{\mathrm{a}}$ ed. - Porto Alegre: Artmed, 2010. 
CERVO, A. L.; BERVIAN; P. A. Metodologia científica. 3. ed. São Paulo: McGraw-Hill do Brasil, 1983

CONSELHO NACIONAL DOS DIREITOS DAS PESSOAS COM DEFICIÊNCIA (CO$\mathrm{NADE}$ ). Nota públicas às autoridades para atenção às pessoas com deficiência. Brasília, 2020. Disponível em: http://www.coede.pr.gov.br/arquivos/File/2020/NotaPublicaConade.pdf. Acesso em 02.07.2020

CORONAVIRUS DISEASE (COVID-19) SITUATION DASHBOARD. World Health Organization, 2020. Disponível em: https://covid19.who.int/. Acesso em: 25.06.2020

ENABLE. Why disability statiscs matter. [2016]. Disponível em: https://www.un.org/disabilities/documents/sdgs/infographic_statistics_2016.pdf. Acesso em 03.07.2020

GIL, A. C. Métodos e Técnicas de pesquisa social. 6ª ed. São Paulo: Atlas, 2008.

HALL, Stuart. A identidade cultural na pós-modernidade. Rio de Janeiro: DP\&A, 2005.

INSTITUTO BRASILEIRO DE GEOGRAFIA E ESTATÍSTICA (IBGE). Censo Brasileiro de 2010. Rio de Janeiro: IBGE, 2012. Disponível em: https://educa.ibge.gov.br/jovens/ conheca-o-brasil/populacao/20551-pessoas-com-deficiencia.html. Acesso em 25.06.2020

IBGE - INSTITUTO BRASILEIRO DE GEOGRAFIA E ESTATÍSTICA. Pesquisa Nacional por Amostra de Domicílios Contínua: Acesso à Internet e à televisão e posse de telefone móvel celular para uso pessoal 2018. Rio de Janeiro: IBGE, 2018. 12 p. (IBGE, Diretoria de Pesquisas, Coordenação de Trabalho e Rendimento, Pesquisa Nacional por Amostra de Domicílios Contínua 2017-2018, ISBN 978-85-240-4527-1).

KOller, S. H.; DE PAUlA, C. M. C. P.; HOHENDORFF, J. V. Manual de Produção Científica. Porto Alegre: Penso, 2014.

MINISTÉRIO DA SAÚDE. Disponível em https://coronavirus.saude.gov.br/. Acesso em 06.07.2020

NEUMANN, Cristina Rollim et al. Pandemia de influeza a (h1n1): o que aprender com ela? Revista HCPA, v.29. P. 92-99. 2009.

RODRIGUES. J. C. Tabu do corpo. Coleção Antropologia e Saúde. $7^{\text {a }}$ ed. Rio de Janeiro: Editora Fiocruz, 2006.

SANTOS. Boaventura de Souza. A Cruel Pedagogia do Vírus. Almedina. 2020.

SAVIANI, D. Crise estrutural, conjuntura nacional, coronavírus e educação - o desmonte da educação nacional. Revista Exitus, Santarém/PA, Vol. 10, p. 01-25, e020063, 2020. 
SIS/IBGE. Síntese de indicadores sociais: uma análise das condições de vida da população brasileira: 2019 / IBGE, Coordenação de População e Indicadores Sociais. - Rio de Janeiro: IBGE, 2019. 130 p. - (Estudos e pesquisas. Informação demográfica e socioeconômica, ISSN 1516-3296; n. 40). Disponível em: https://biblioteca.ibge.gov.br/index.php/ biblioteca-catalogo? view $=$ detalhes\&id=2101678. Acesso em: 05/07/2020.

TOMÁS, J. C. S. P. A invisibilidade social, uma perspectiva fenomenológica. In: VI CONGRESSO PORTUGUÊS DE SOCIOLOGIA, 6., 2008, Lisboa. Anais ... Lisboa. 2008.

World Health Organization. Disponível em: https://www.who.int/. Acesso em 02.07.2020.

Wolrd Wide Web Consortium. Disponível em: https://www.w3.org/. Acesso em 02.07.2020.

Wolrd Wide Web Consortium. Disponível em: https://w3c.br/. Acesso em 02.07.2020.

\section{DAdOS DOS AUTORES}

\section{Josivan Jỗo Monteiro Raiol}

Doutorando do Programa de Pós-Graduação em Educação Especial da Universidade Federal de São Carlos (UFSCar). Membro do Núcleo de Estudos e Pesquisa em Direito à Educação - Educação Especial -NEPEDE - EEs (UFSCar/São Carlos. Professor atuando como formador no Centro de Formação de Profissionais da Educação Básica (CEFOR) pela Secretaria Estadual de Educação do Pará (SEDUC). josivan.raiol@gmail.com

\section{Rosimeire Maria OrLando}

Doutora em Educação Escolar pela Universidade Estadual Paulista Júlio de Mesquita Filho (UNESP) e pós-doutora pela Universidade Federal de São Carlos - Departamento de Psicologia (UFSCar) e pela Universidade Estadual de Londrina (UEL/Londrina). Coordenadora do Núcleo de Estudos e Pesquisa em Direito à Educação - Educação Especial (UFSCar/ São Carlos). Professora adjunta IV, na Universidade Federal de São Carlos, licenciatura em Educação Especial e no Programa de Pós-Graduação em Educação Especial/UFSCar. meiremorlando@gmail.com

\section{Eduardo ThomazinI}

Licenciando em Educação Especial na Universidade Federal de São Carlos (UFSCar), São Carlos/SP.zakkythomaz@gmail.com

Submetido em: 03-11-2020

Aceito em: 07-07-2021 